\title{
Effect of Surface Treatment on Longevity of Soft Liners: An in vitro and in vivo Study
}

\author{
${ }^{1}$ Manoj K Thakur, ${ }^{2}$ Dharmendar K Singh
}

\section{ABSTRACT}

Aim: Soft liners are temporary in nature as they harden in short time period and gradually lose their surface integrity and cushioning effect. There is a need to increase the longevity of the soft liner, so the present investigation was done in order to study the effect of surface treatment in increasing the longevity of soft liner, both in in vitro and in vivo conditions.

Materials and methods: For an in vitro study, specimens were prepared and divided into two equal groups. Group I (control group) specimens were lined with soft liner and left uncoated and group II (treated group) specimens were lined with soft liner and were coated by surface conditioning agent. For an in vivo study, 20 patients were selected and divided into two groups. Group I (control group) patients wore denture lined with uncoated soft liner, whereas group II (treated group) patients wore denture lined with soft liner and coated with surface conditioning agent. Soft liners lining the specimens and dentures were then examined for softness with a durometer and for surface integrity with a scanning electron microscope (SEM) at the baseline and after 1,2 , and 3 weeks.

Results: Mean softness of the control group decreased significantly than the treated group, both in in vitro and in vivo conditions at the end of third week, but the decrease in softness was found to be more in in vivo condition than in vitro condition. Both in in vivo and in vitro conditions, SEM analysis showed that surface integrity in the control group had deteriorated by the end of first week, whereas that in the treated group remained intact until the end of the third week in in vitro condition and until the end of second week in in vivo condition.

Conclusion: Our results suggest that surface coating can significantly reduce the loss of softness and surface integrity of the soft liners, and hence increases their longevity both in in vitro and in vivo conditions.

Keywords: Coating, Dentures, In vitro, In vivo, Soft liner, Specimen.

How to cite this article: Thakur MK, Singh DK. Effect of Surface Treatment on Longevity of Soft Liners: An in vitro and in vivo Study. Int J Prosthodont Restor Dent 2018;8(1):17-21.

\footnotetext{
${ }^{1}$ Senior Resident, ${ }^{2}$ Professor

${ }^{1}$ Department of Dental Surgery, Nalanda Medical College \& Hospital, Patna, Bihar, India

${ }^{2}$ Department of Prosthodontics, Faculty of Dental Sciences Patna Dental College \& Hospital, Patna, Bihar, India

Corresponding Author: Manoj K Thakur, Senior Resident Department of Dental Surgery, Nalanda Medical College \& Hospital, Patna, Bihar, India, Phone: +919507264670, e-mail: mnjkgmc@gmail.com
}

Source of support: Nil

Conflict of interest: None

\section{INTRODUCTION}

Use of soft liners has been found to be clinically effective for the management of damaged tissue underlying ill-fitting dentures, functional impressions, temporary relining of ill-fitting dentures, and also for maxillofacial prosthesis and immediate dentures. Conditioning of soft tissues underlying dentures by soft liners is effective in relieving the pain, discomfort, and inflammation associated with ill-fitting dentures. ${ }^{1}$ Soft liners confirm to the anatomy of the residual ridge and gel in that position and continue to flow slowly after application. The purpose of the soft liner is to absorb some of the energy produced by masticatory impact that would otherwise be transmitted through the denture to the soft mucosal tissues, thus acting as cushion. There are two types of soft relining materials: Temporary and permanent. The temporary soft relining material can be used up to a few weeks after which they begin to foul smell and de-bond from the denture. Hence this material has to be replaced often. The permanent soft relining material (processed soft liners) is used in a patient who is wearing a complete denture and experiencing chronic soreness with their dentures, may be because of heavy bruxism or poor oral health. These materials are processed in the laboratory in a manner similar to denture base. They may remain resilient up to a year. ${ }^{2}$

These soft lining materials are mainly made up of polyethylmethacrylate or polymethylmethacrylate resin added with plasticizer such as dibutyl phthalate or ethanol. ${ }^{3}$ Both alcohol and plasticizers of soft liners leach out and are partially replaced by water. The material thus hardens within a considerable short period of time and gradually loses its surface integrity and cushioning effect. ${ }^{4}$ This leads to increasing vulnerability, deterioration, contamination, and creation of a foul odor by microorganisms, which in turn can lead to further irritation of the already damaged mucosal tissues.

Longevity of soft liners can be extended by different treatments and surface coating. Nimmo et $\mathrm{al}^{5}$ found that vacuum-treated Visco-gel produced a denser, less porous mix and improved the surface texture; however, microbial 
adhesion was not affected by vacuum treatment. Corwin and Saunders ${ }^{6}$ suggested a modified polymerization technique (intraoral curing for 10-15 minutes, followed by autoclaving with water at $43-46^{\circ} \mathrm{C}$ for $20-30$ minutes at $25-30 \mathrm{psi}$ ) that would extend the useful clinical life of Lynal soft liner (LD Caulk, Dentsply International). Gardner and Parr $^{7}$ studied that the long-term effectiveness of temporary soft liners (Soft Oryl, Teledyne Getz, Elk Grove Village, Illinois, USA) can be extended up to 1 year by coating with Monopoly, a polymethylmethacrylate resin coating. Further, Casey and Scheer ${ }^{8}$ reported that surface treatments with Monopoly glaze on soft liner (Coe-Soft, Coe Laboratories Inc., Chicago, Illinois, USA) lead to improved glassy surface of the soft liner that lasted for 30 days intraorally. It was also reported that soft liner coated with Monopoly appeared to lose alcohol, but it did not absorb water in vitro in addition to no loss of plasticizer was observed over the 30-day test period. ${ }^{9}$ Effect of coating of soft liners with Palaseal (Heraeus Kulzer, South Bend, IN, USA) or Monopoly for improvement in their resiliency was studied and a significant increase in the resiliency of Lynal (LD Caulk, Dentsply International, Milford, Delaware, USA) was obtained in specimens coated with Palaseal, Monopoly, and Visco-gel (DeTrey / Dentsply, Weybridge, UK); however, no difference was found between uncoated and coated specimens of CoeSoft. ${ }^{10}$ Hayakawa et $a l^{11}$ found that the fluorinated copolymer coating Kreguard (Kureha, Tokyo, Japan) imparted an improved glossy surface to a soft liner, thus possibly increasing its useful life. Malmstrom et $\mathrm{al}^{12}$ reported the effect of two different coatings on the surface integrity and softness of a soft liner (Coe-Comfort, GC America Inc., Alsip, Illinois, USA) and concluded that coating significantly reduced the loss of softness and surface integrity of the conditioner.

Currently available soft liner Visco-gel although possesses all quality of soft liner, but needs to be replaced at short intervals, which is time-consuming and costly for both the dentist and the patient. Therefore, there is a need to improve the working life of this material. The present study was designed to evaluate the effect of surface treatment on adequate softness and surface integrity of the soft liner, Visco-gel.

\section{MATERIALS AND METHODS}

\section{Preparation of Resin Disks and Dentures}

For in vitro studies disks of the heat-cured resin (Dentsply DeTrey $\mathrm{GmbH}$, Germany) were prepared at a powder/ liquid ratio of $2.5: 1$ by weight. The resin disks were prepared by investing a 2-mm-thick brass spacer of the same thickness but of a different shape, i.e., circular and triangular, to allow differentiation between the control (group I) and the tested (group II) samples. The heatcured resin was mixed, packed into the mold with the brass spacer, and processed in a water bath at $74^{\circ} \mathrm{C}$ for 8 hours. Denture-based resin disks group I (control) were circular with a diameter of $1 \mathrm{~cm}$ and thickness of $2 \mathrm{~mm}$, lined with soft liner and left uncoated, whereas denturebased resin disks of group II (treated) were triangular with a diameter of $1 \mathrm{~cm}$ and thickness of $2 \mathrm{~mm}$, lined with soft liner and coated with the surface conditioning agent. For in vivo study, complete dentures were prepared following standard procedure. Complete dentures wore by group I (control) patients were lined with soft liner but not treated with surface conditioning agent (coating) whereas complete dentures wore by group II (treated) patients were lined with soft liner and were also treated with surface conditioning agent.

\section{Surface Conditioning Agent (Coating)}

This was used for coating the soft liner. It was prepared by mixing one part of clear acrylic resin polymer by weight to 10 parts of heat-cured acrylic resin monomer. The monomer was poured into a Pyrex beaker and placed in a pan of water at $54^{\circ} \mathrm{C}$. When the monomer was warm, the polymer was allowed to mix slowly with the monomer while stirring continuously with a glass rod. After 10 minutes, the solution became viscous. It was then cooled to room temperature, poured into a dark glass bottle, and refrigerated. Treated group specimens and dentures were coated with the surface conditioning agent.

\section{Artificial Saliva}

Artificial saliva was prepared using the method of Katz et $\mathrm{al}^{13}$ and was used for in vitro study.

\section{Test for Softness}

Durometer (Model 411, ASTM Type OO; PTC Instruments, Los Angeles, California, USA) was used to evaluate the softness of the soft liner. For in vitro study, the specimens were immersed in artificial saliva at room temperature until testing with a durometer on regular interval. Readings were taken with measuring scale when it becomes almost constant. For in vivo study, patients was advised to wear complete denture regularly until testing with a durometer on regular interval. The readings were taken with measuring scale when it becomes almost constant. The hardness of supporting structure affects the observed specimen and denture softness, therefore specimens and dentures were placed on hard table. The lower point in the measuring scale indicates greater softness. The softness of soft liner of all the specimens and denture were evaluated during regular interval. The readings were measured on the ASTM scale of durometer. 


\section{Test for Surface Integrity}

Changes in the surface integrity of the soft liner were analyzed by SEM. Test specimens immersed in artificial saliva and dentures wore by patients were taken out and air dried for 30 minutes. The dried specimens and dentures were then mounted on an aluminum stub with the help of electro-conductive material. They were transferred to the sputter coater for gold coating. After gold coating they were removed and placed in a rotating platform chamber of SEM. Changes in regard to surface integrity were evaluated during regular interval.

\section{Statistical Analysis}

Student's t-test was done to do paired comparisons and differences were considered statistically significant at $\mathrm{p}<0.001$.

\section{RESULTS}

In case of in vitro study, the specimens of both groups were tested with the durometer after immersion in artificial saliva at room temperature at various intervals. Table 1 shows the mean surface softness score for in vitro study at different time intervals. At the beginning, the mean surface softness score for group I was $65.2 \pm 1.229$ and for group II it was $61.5 \pm 1.08$. After 1 week the mean surface softness score for group I was $69.6 \pm 1.43$ and for group II it was $64.1 \pm 2.025$. After 2 weeks, the mean surface softness score for group I was $74.8 \pm 1.814$ and for group II it was $66.6 \pm 1.075$. After 3 weeks, the mean surface softness score for group I was $79.5 \pm 1.509$ and for group II it was $68.6 \pm 1.174$. The statistical comparison revealed that the mean surface softness score of group I (control) was significantly higher $(\mathrm{p}<0.0001)$ as compared with that of group II (treated) at each determined time points. This shows that the surface coating retains the softness of the specimens.
In case of in vivo study, surface conditioner lining dentures wore by patients of both groups were tested with durometer at various intervals. Table 2 shows the mean surface softness score for in vivo study at different time intervals. The mean surface softness score of dentures of group I was $65.9 \pm 0.875$ and in group II it was $62.9 \pm$ 0.875 in the beginning. After 1 week, the mean surface softness score of group I was $69.4 \pm 1.35$ and for group II was $64.9 \pm 0.875$. After 2 weeks, the mean surface softness score of group I was $77.3 \pm 1.494$ and group II was 69.0 \pm 0.942 . After 3 weeks, the mean surface softness score for group I was $83.2 \pm 1.476$ and of group II it was $78.2 \pm$ 1.229. The statistical comparison revealed that the mean surface softness score of group I was significantly higher $(p<0.001)$ as compared with that of group II. Thus at each determined time points, the mean surface softness score of group II was significantly $(p<0.001)$ lower than that of group I, which shows that treated dentures are softer. Change in softness score at the end of third week from baseline was more in case of in vivo condition as compared with in vitro condition.

The surface integrity of the soft liner lining the specimens and dentures were studied by SEM. In case of in vitro study, the SEM analysis indicated that the surface integrity of the soft liner of group I deteriorated with time, whereas that of group II remained intact up to the end of the third week (Fig. 1). In control and treated group the entire surface of the soft liner was covered by a uniform layer of surface conditioning agent at baseline. After 1 week, the surface of control group started deteriorating but in treated group the surface remains free of beads up to third week, indicating that alcohol had not leached out due to the integrity of the surface conditioning. Similar results were obtained in case of in vivo study, but surface deterioration was faster as compared with in vitro study (Fig. 2).

Table 1: Mean softness score of specimen of two groups at different time points after immersion in artificial saliva

\begin{tabular}{|c|c|c|c|c|c|c|}
\hline \multirow[b]{2}{*}{ Time interval } & \multicolumn{2}{|c|}{ Softness (mean $\pm S D$ ) } & \multicolumn{2}{|c|}{ Change from baseline } & \multirow[b]{2}{*}{$t$-value } & \multirow[b]{2}{*}{$p$-value } \\
\hline & Group I & Group II & Group I & Group II & & \\
\hline Beginning & $65.2 \pm 1.229$ & $61.5 \pm 1.08$ & - & - & 7.150 & $<0.0001$ \\
\hline After 1 week & $69.6 \pm 1.43$ & $64.1 \pm 2.025$ & $4.4 \pm 1.0749$ & $2.6 \pm 2.22$ & 7.017 & $<0.0001$ \\
\hline After 2 weeks & $74.8 \pm 1.814$ & $66.6 \pm 1.075$ & $9.6 \pm 1.646$ & $5.1 \pm 1.44$ & 12.30 & $<0.0001$ \\
\hline After 3 weeks & $79.5 \pm 1.509$ & $68.6 \pm 1.174$ & $14.3 \pm 1.55$ & $7.1 \pm 1.19$ & 18.03 & $<0.0001$ \\
\hline
\end{tabular}

Table 2: Mean softness score of dentures worn by patients of two groups at different time points

\begin{tabular}{|c|c|c|c|c|c|c|}
\hline \multirow[b]{2}{*}{ Time interval } & \multicolumn{2}{|c|}{ Softness (mean $\pm S D$ ) } & \multicolumn{2}{|c|}{ Change from baseline } & \multirow[b]{2}{*}{$t$-value } & \multirow[b]{2}{*}{$p$-value } \\
\hline & Group I & Group II & Group I & Group II & & \\
\hline Beginning & $65.9 \pm 0.875$ & $62.9 \pm 0.875$ & - & - & 7.66 & $<0.0001$ \\
\hline After 1 week & $69.4 \pm 1.35$ & $64.9 \pm 0.875$ & $3.5 \pm 1.50$ & $2 \pm 1.49072$ & 8.84 & $<0.0001$ \\
\hline After 2 weeks & $77.3 \pm 1.494$ & $69.0 \pm 0.942$ & $11.4 \pm 1.83$ & $6.1 \pm 1.19729$ & 14.85 & $<0.0001$ \\
\hline After 3 weeks & $83.2 \pm 1.476$ & $78.2 \pm 1.229$ & $17.3 \pm 1.94$ & $15.3 \pm 1.33744$ & 8.23 & $<0.0001$ \\
\hline
\end{tabular}




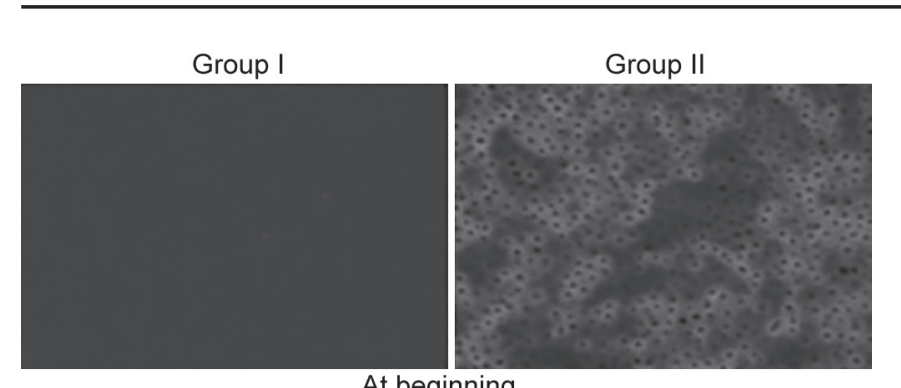

At beginning

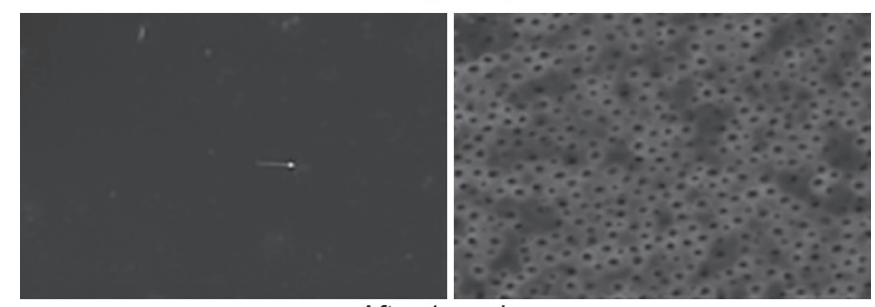

After 1 week

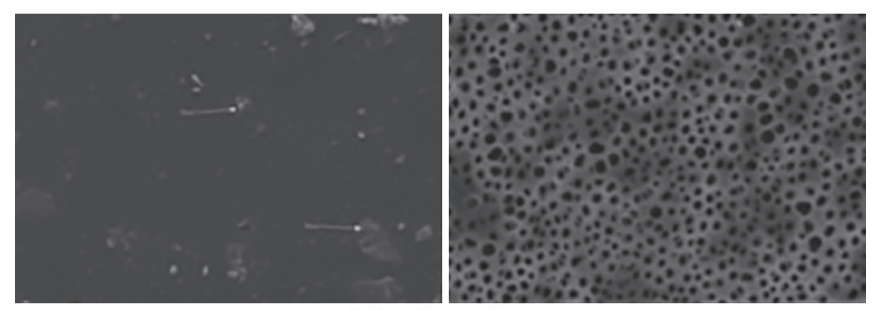

After 2 weeks

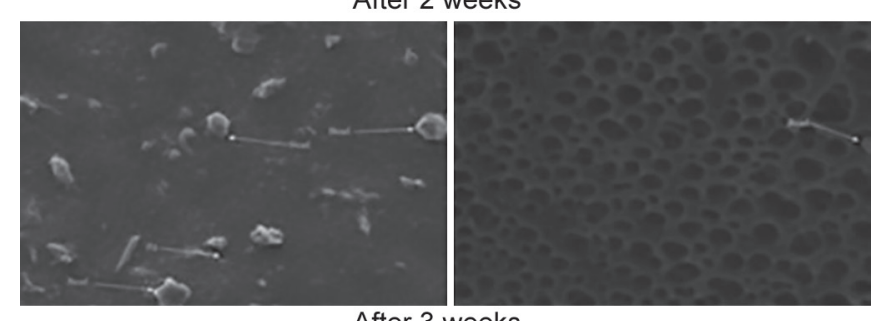

After 3 weeks

Fig. 1: Scanning electron microscopy picture of in vitro study

\section{DISCUSSION}

Results of our study show a regular increase in the mean softness score of the surface conditioner after increasing periods, both in in vitro and in vivo studies. However, as compared with control untreated group, this change was almost half in the treated group. This shows that coating of surface conditioner retained its softness for longer time, perhaps due to a reduction in the rate of leaching of the plasticizer, as well as the penetrant (alcohol) as per finding of Gronet et al. ${ }^{10}$ It is also possible that surface-coated soft liners prevent the absorption of salivary inorganic salts, which may be a contributing factor to the hardening process. ${ }^{14}$

The SEM analysis of control and surface-coated soft liners lining the specimens and dentures showed that the surface integrity of uncoated soft liners deteriorated faster than the coated one. This is in line with the report of Casey and Scheer, ${ }^{8}$ who reported that coating of Monopoly intraorally preserved the surface integrity of

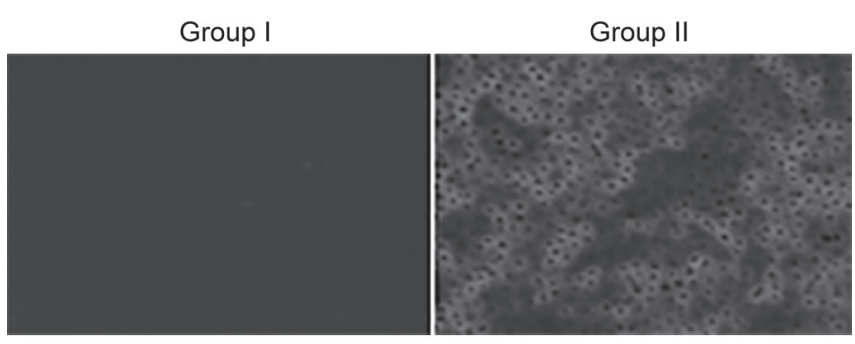

At beginning

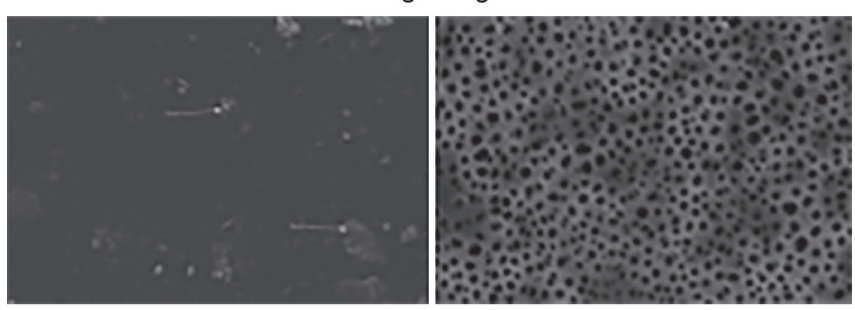

After 1 week
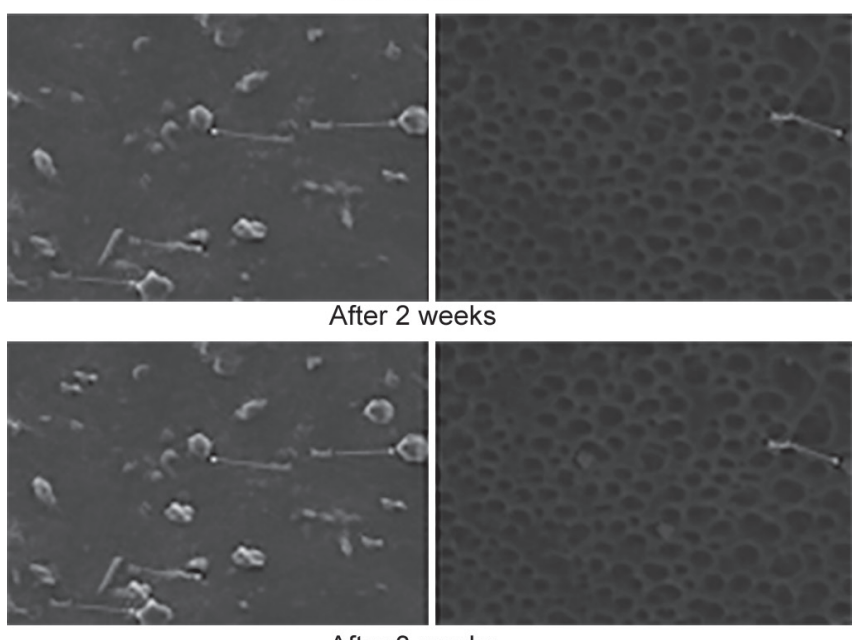

After 3 weeks

Fig. 2: Scanning electron microscopy picture of in vivo study

the temporary soft liner; Coe-Soft for at least 30 days. The probable reason for this may be due to loss of alcohol which act as a catalyst for plasticizer and more absorption of water as reported by Dominguez et al, ${ }^{9}$ who showed that surface coating of soft liner prevents loss of plasticizer and thus maintains their surface integrity. Besides this, we have observed greater loss of softness and surface integrity in in vivo condition as compared with in vitro condition. This may be due to masticatory force applied on denture during chewing.

The result of this study suggested that surface coating may allow soft liner to function longer than currently recommended by manufacturer before replacement. Further clinical studies need to be conducted to confirm this study.

\section{REFERENCES}

1. Harrison. A. Temporary soft lining materials:A review of their uses. Br Dent J 1981;151:419-422. 
2. Murata H, Hamada T, Djulaeha E, Nikawa H .Rheology of tissue conditioners. J Prosthet Dent 1998;79:188-199.

3. Braden M. Soft liners: II. Rheologic properties. J Dent Res 1970;49:496-501.

4. Ellis B, Lamb DJ, Al-Nakash S. Water sorption by a soft liner. J Dent Res 1977 Dec;56(12):15-26.

5. Nimmo A, Fong BJ, Hoover CI, Newbrun E. Vacuum treatment of soft liners. J Prosthet Dent 1985;54:814-817.

6. Corwin JO, Saunders TR. Temporary soft liners: a modified curing technique to extend liner longevity. J Prosthet Dent 1992 Oct;68(4):714-715.

7. Gardner LK, Parr GR, Rahn AO. Combination nasal support breathing flange with hollow obturator prosthesis. A clinical report. J Prosthet Dent 1990 May;63(5):497-501.

8. Casey DM, Scheer EC. Surface treatment of a temporary soft liner for increased longevity. J. Prosthet Dent 1993 Mar;69(3):318-324.
9. Dominguez NE, Thomas CJ, Gerzina TM. Soft liners protected by a poly (methyl methacrylate) coating. Int J Prosthodont 1996 Mar-Apr;9(2):137-141.

10. Gronet PM, Driscoll CF, Hondrum SO. Resiliency of surfacesealed temporary soft denture liners. J Prosthet Dent 1997 Apr;77(4):370-374.

11. Hayakawa I, Takahashi Y, Morizawa M, Kobayashi S, Nagao M. The effect of fluorinated copolymer coating agent on tissue conditioners. Int J Prosthodont 1997 Jan-Feb;10(1):44-48.

12. Malmstrom HS, Mehta N, Sanchez R, Moss ME. The effect of two different coatings on the surface integrity and softness of a soft liner. J Prosthet Dent 2002 Feb;87(2):153-157.

13. Katz S, Park KK, Stookey GK, Schemehorn BR. Development and initial testing of a model for in vitro formation of pit and fissure caries. Caries Res 1986;20(5):424-428.

14. Wilson J. In vitro loss of alcohol from soft liner. Int J Prosthodont 1992 Jan-Feb;5(1):17-21. 